\title{
Second-line Treatment of Stage III/IV Non-Small- Cell Lung Cancer (NSCLC) with pemetrexed in routine clinical practice: Evaluation of performance status and health-related quality of life
}

Wolfgang Schuette ${ }^{1}$, Hans Tesch ${ }^{2}$, Hartwig Büttner ${ }^{3}$, Thomas Krause ${ }^{3}$, Victoria Soldatenkova ${ }^{4}$ and Clemens Stoffregen ${ }^{3 *}$

\begin{abstract}
Background: Second-line treatment of advanced non-small-cell lung cancer (NSCLC) improves overall survival. There is a lack of data regarding the impact on patients' overall health condition. This prospective, noninterventional study evaluated performance status (PS) and health-related quality of life (HR-QoL) during secondline pemetrexed treatment in routine clinical practice.

Methods: Stage III/IV NSCLC patients who initiated second-line pemetrexed (standard vitamin and dexamethasone supplementation) were observed for a maximum of 9 treatment cycles. The primary objective was to evaluate the proportion of patients achieving improvement of Karnofsky Index (KI) of $\geq 10 \%$ (absolute) or maintaining KI $\geq 80 \%$ after the second treatment cycle ("KI benefit response"). HR-QoL was self-rated using the EuroQoL-5D questionnaire (EQ-5D). Factors potentially associated with $\mathrm{KI}$ benefit response were evaluated using logistic regression models.

Results: Of 521 eligible patients (73.5\% Stage IV, median age $66.3 \mathrm{yrs}, 36.1 \% \geq 70 \mathrm{yrs}, 62.0 \%$ with $\mathrm{KI} \geq 80 \%$ ), 471 (90.4\%) completed at least 2 treatment cycles. 58.0\% (95\% CI 53.6\%;62.2\%) achieved Kl benefit response after the second cycle. Patients with baseline $\mathrm{KI} \geq 80 \%$, no Grade $3 / 4$ toxicities during the first 2 cycles, or combination regimen as prior first-line therapy were more likely to achieve a KI benefit response. EQ-5D scores improved over time. Grade 3/4 toxicities were reported in 23.8\% of patients (mainly fatigue/asthenia 15.9\%, neutropenia 8.7\%).

Conclusions: In this large prospective, non-interventional study of second-line pemetrexed treatment in patients with advanced NSCLC, including 36\% elderly patients ( $\geq 70$ years), physician-rated PS and self-rated HR-QoL were maintained or improved in the majority of patients.
\end{abstract}

Trial registration: Registered on ClinicalTrials.gov (NCT00540241) on October 4, 2007

\section{Background}

Second-line treatment of advanced non-small-cell lung cancer (NSCLC) improves overall survival (OS), although the survival benefit is still limited (6-8 months) [1-4]. Because the most important purpose of secondline treatment is palliation, maintenance or improvement of a patient's overall health condition is a highly relevant treatment benefit. However, there is a lack of

\footnotetext{
*Correspondence: Stoffregen_clemens@lilly.com

${ }^{3}$ Medical Department, Lilly Deutschland GmbH, Bad Homburg, Werner-

Reimers Straße 2-4, 61352 Bad Homburg, Germany

Full list of author information is available at the end of the article
}

prospective data regarding the impact of second-line treatment on a patient's overall health condition [5]. Patients' overall health condition can be evaluated by looking at their performance status (PS) as rated by a physician, and/or by looking at health-related quality of life (HR-QoL) as rated by the patient themselves. While several clinical studies have shown that patient-rated HR-QoL improves during second-line NSCLC treatment $[2,6,7]$, no study has specifically looked at changes in physician-rated PS. In addition, the few studies that have compared patient-and physician-rated outcomes

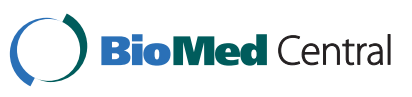

() 2011 Schuette et al; licensee BioMed Central Ltd. This is an Open Access article distributed under the terms of the Creative Commons Attribution License (http://creativecommons.org/licenses/by/2.0), which permits unrestricted use, distribution, and reproduction in any medium, provided the original work is properly cited. 
indicate that physicians tend to rate PS better than the patients themselves [8-11].

We designed a prospective, non-interventional multicenter study in patients whose disease had progressed after first-line chemotherapy for Stage III/IV NSCLC and who were about to start second-line treatment with pemetrexed, to evaluate physician-rated PS and patientrated HR-QoL during second-line treatment in routine clinical practice. Due to the observational nature of this study, we expected the patient population to be less selected, including a significant proportion of patients with poor PS, as well as elderly patients. For these populations, there is a particular lack of prospective data on tumor response, survival and HR-QoL [12,13]. Elderly patients are of special interest; they are rarely enrolled into clinical trials, but more than two thirds of NSCLC cases are diagnosed in patients aged $\geq 65$ years [13]. The primary objective of this study was to evaluate the proportion of patients who achieved an improvement of Karnofsky Index (KI) or maintained a KI $\geq 80 \%$ after the second cycle of pemetrexed treatment ("KI benefit response").

\section{Methods}

\section{Patient population}

Adult patients with NSCLC Stage IIIa/b or IV who were about to start second-line treatment with single-agent pemetrexed at the physician's discretion were eligible to participate in this non-interventional study. NSCLC staging was based on the fifth edition of the TNM classification [14] because the study began in 2007.

Pemetrexed has been approved in the USA and Europe for the treatment of patients with advanced NSCLC in the second-line setting since 2004. In 2008, new pemetrexed first-line data revealed that patients with predominantly non-squamous histology have a particular survival benefit $[15,16]$. Accordingly, the second-line indication for pemetrexed was revised to include patients with advanced NSCLC of predominantly nonsquamous histology only. Because our study began in 2007 , i.e. before the label change, patients with both squamous and non-squamous histology participated in the study.

Patients were eligible if they had already received one previous cytotoxic chemotherapy regimen; combination with a targeted agent like erlotinib was allowed. However, patients who initially received a targeted agent only and later received cytotoxic chemotherapy were not eligible, because the initial targeted agent treatment would have been regarded as first-line treatment. Previous pemetrexed treatment was not allowed. Physicians routinely involved in the treatment of NSCLC were asked to participate in the study. In- and outpatients were enrolled at 102 hospitals and practices in Germany
(100 sites) and Austria (3 sites) between 09/2007 and $08 / 2009$. All patients provided authorization for the use and disclosure of their data collected during this noninterventional study. The study protocol was reviewed by ethical review boards in Germany and Austria (Ethics Committee of the Landesärztekammer Hessen, Frankfurt, Germany; Ethics Committee of the Country of Oberösterreich, Linz, Austria).

\section{Study design}

This prospective, non-interventional phase IV multicenter study (NCT00540241; H3E-SB-B007) evaluated changes in physician-rated PS and patient-rated HRQoL during second-line treatment with pemetrexed in routine clinical practice. The primary objective was to evaluate the proportion of patients who achieved either an improvement of KI of at least 10\% (absolute) or maintained a high KI of at least $80 \%$ ("KI benefit response") after the second cycle of second-line pemetrexed treatment, and to identify factors which may be associated with a benefit in KI. The KI benefit response was primarily assessed after the second cycle because physicians routinely evaluate patients' clinical and functional status thoroughly after the second treatment cycle, and most patients can be expected to still be on treatment. Secondary outcomes included patient-rated HR-QoL (European Quality Of Life Five Dimensions questionnaire [EQ-5D]), reasons for treatment discontinuation, evaluation of prior chemotherapy, OS, physician-rated disease control, solicited toxicities, weight loss, and use of solicited disease- or treatment-related concomitant medications.

\section{Treatment}

It was assumed that physicians would administer pemetrexed in accordance with the indication for second-line treatment, as outlined in the current Summary of Product Characteristics (SPC) for the respective countries. According to the SPC, pemetrexed was to be administered every 21 days ( 1 treatment cycle) at a dose of 500 $\mathrm{mg} / \mathrm{m}^{2}$, using standard vitamin supplementation and dexamethasone prophylaxis. Any use of further concomitant medication was at the physician's discretion. The duration of pemetrexed treatment was also at the discretion of the physician. In clinical studies, second-line pemetrexed treatment is commonly given over a median of 4 cycles, with few patients exceeding 6 cycles [6]. In this non-interventional study, patients were observed for a maximum of 9 treatment cycles (treatment continued at physician discretion).

\section{Assessments}

The baseline visit was to be scheduled approximately 1 week before administration of the first dose of 
pemetrexed. On-treatment data were to be collected on day 1 of each treatment cycle, up to the last dose of pemetrexed, but no longer than a maximum of 9 visits. Final data were collected approximately 21 days after the last recorded dose of pemetrexed. Following the last patient visit, all participating physicians were contacted once to collect final follow-up information on patient survival.

Physician-rated KI [17], dose and administration of pemetrexed, body weight, solicited relevant concomitant medications (including vitamin $\mathrm{B}_{12}$ supplementation) and survival status were collected at each visit. Overall best response as evaluated by the physician was collected at the final visit. The following solicited toxicities were collected as maximum toxicity grades (none, Grade 1/2, Grade 3/4) at each visit: neutropenia, febrile neutropenia, mucositis, stomatitis, pharyngitis, fatigue, asthenia, nausea, vomiting, diarrhea, and rash/desquamation. An electronic data capture system was used to collect these data. In addition, patients were asked to document folic acid intake in patient diaries and to complete the EQ-5D questionnaire [18] at each visit. The questionnaire comprises 5 dimensions of health (mobility, self-care, usual activities, pain/discomfort, anxiety/depression). Each dimension comprises three levels (some, moderate, extreme problems, rated from 13). An overall EQ-5D index was calculated [19], with an index of 1.0 representing full health. In addition, patients evaluated their current health state on a visual analogue scale (EQ-Visual Analogue Scale [VAS]; 0 = worst, 100 = best imaginable health state).

\section{Statistics}

Approximately 580 patients were planned to be observed. Assuming a 5\% drop-out rate, this sample size would allow the $95 \%$ confidence interval (CI) for the proportion of patients showing a "KI benefit response" to range between $3.6 \%$ (for an observed proportion of $4.9 \%$ ) and $8.4 \%$ (for an observed proportion of $50 \%$ ).

Data analyses were exploratory and performed using SAS software (Statistical Analysis System Release 9.2, SAS Institute). All eligible patients were included in the primary analysis of KI benefit response. Those patients who discontinued prior to the end of the second treatment cycle or who had missing values concerning KI were considered as non-responders in terms of KI benefit response in the primary analysis (worst case scenario). In a second, supportive approach, the analysis was based on all patients who had non-missing data for KI at baseline and after 2 cycles of treatment. For both proportion estimates, $95 \%$ CIs based on the F distribution method were provided [20].

Factors potentially associated with achieving a KI benefit response were investigated using logistic regression analysis (univariate and multivariable modeling approaches).

Changes from baseline in EQ-5D index and EQ-VAS scores were explored using two-sided t-tests or signtests in case of failed normality assumptions. EQ-5D individual domains, disease control (defined as best response of complete response, partial response or stable disease as evaluated by physician), body weight, concomitant medications and toxicities were analyzed by descriptive statistics. Reasons for discontinuation, type of prior chemotherapy, and solicited toxicities were presented by decreasing frequency. OS was measured from the date of the first pemetrexed dose to the date of death due to any cause. If survival status was unknown at the final follow-up, OS time was censored at the last contact date. The median OS time was estimated using the product limit method [21]. The associated 95\% CI was based on the sign test [22]. Followup time was quantified using the "reversed" KaplanMeier method [23].

\section{Results}

\section{Patient disposition}

Of 542 NSCLC patients with any documentation available, 521 (96.1\%) patients were eligible for analysis. One patient was excluded because he had received no previous chemotherapy, 19 patients because they had received more than 1 chemotherapy regimen prior to study entry. One patient had been set up in the electronic data capture system before any treatment decision was made and was excluded because there was no further documentation and no plan to start second-line pemetrexed treatment. Of the 521 eligible patients with baseline data, 516 (99.0\%) received at least one dose of pemetrexed ( 2 patients died before the first dose, 3 patients were lost to follow-up or had missing data). 471 patients $(90.4 \%)$ completed at least 2 cycles of pemetrexed treatment. 254 patients $(48.8 \%)$ completed at least 6 , and $110(21.1 \%)$ at least 9 treatment cycles. 25 patients $(4.8 \%)$ continued pemetrexed after the end of the observational period. A median of 5 treatment cycles (range 1 to 9) were documented.

Of all patients treated ( $\mathrm{N}=516), 28.9 \%$ completed the treatment schedule as planned by the physician. The most frequent reasons for early discontinuation of pemetrexed were disease progression $(27.7 \%)$, followed by death (14.3\%), patient decision (14.1\%), toxicity (4.5\%), other reasons (3.9\%) and loss to follow-up (1.2\%).

\section{Patient characteristics}

Table 1 presents the baseline characteristics for all eligible patients $(\mathrm{N}=521)$. The majority of all patients (73.5\%) had Stage IV disease, $37.8 \%$ of patients had a poor baseline KI of $<80 \%$. Patients overall had a median 
Table 1 Baseline characteristics, all patients

\begin{tabular}{|c|c|}
\hline & All patients $(\mathrm{N}=521)$ \\
\hline \multicolumn{2}{|l|}{ Age } \\
\hline Years, median (range) & $66.3(39-86)$ \\
\hline$\geq 70$ years, $\mathrm{n}(\%)$ & $188(36.1)$ \\
\hline Gender, n (\%) male & $363(69.7)$ \\
\hline Origin, $\mathrm{n}(\%)$ Caucasian & $514(98.7)$ \\
\hline Weight, kg [mean (SD)] & $74.9(14.45)$ \\
\hline \multicolumn{2}{|l|}{ Smoking status, n (\%) } \\
\hline Current smoker & $139(26.7)$ \\
\hline Ex-smoker & $243(46.6)$ \\
\hline Never smoked & $138(26.5)$ \\
\hline Missing data & $1(0.2)$ \\
\hline \multicolumn{2}{|l|}{ Histology, n (\%) } \\
\hline Non-squamous cell carcinoma & $444(85.2)$ \\
\hline Squamous cell carcinoma $^{a}$ & $77(14.8)$ \\
\hline \multicolumn{2}{|l|}{ Disease stage at study entry, $\mathrm{n}(\%)$} \\
\hline Stage IIla & $35(6.7)$ \\
\hline Stage IIIb & $103(19.8)$ \\
\hline \multirow[t]{2}{*}{ Stage IV } & $383(73.5)$ \\
\hline & All patients $(\mathrm{N}=521)$ \\
\hline \multicolumn{2}{|l|}{ Karnofsky Index (KI), n (\%) } \\
\hline $\mathrm{Kl} \geq 80 \%$ & $323(62.0)$ \\
\hline KI 70\% & $134(25.7)$ \\
\hline $\mathrm{Kl} 60 \%$ & $45(8.6)$ \\
\hline $\mathrm{KI} 50 \%$ & $18(3.5)$ \\
\hline Missing data & $1(0.2)$ \\
\hline \multicolumn{2}{|l|}{ Type of previous first-line chemotherapy } \\
\hline Platinum-based combinations, n (\%) & $450(86.4)$ \\
\hline Platinum-free combinations, n (\%) & $12(2.3)$ \\
\hline Single-agent, n (\%) & $59(11.3)$ \\
\hline \multicolumn{2}{|l|}{ Most frequent agents used (at least $10 \%$ of patients), $\mathrm{n}(\%)^{\mathrm{b}}$} \\
\hline Carboplatin & $327(62.8)$ \\
\hline Cisplatin & $135(25.9)$ \\
\hline Vinorelbine & $162(31.1)$ \\
\hline Gemcitabine & $159(30.5)$ \\
\hline Paclitaxel & $131(25.1)$ \\
\hline Duration of previous first-line chemotherapy, months [median (range)] & $3.5(0-32)$ \\
\hline Time elapsed since previous first-line chemotherapy, months [median (range)] & $3.9(0-74)$ \\
\hline \multicolumn{2}{|l|}{ Patients [n (\%)] who started pemetrexed } \\
\hline Immediately after end of first-line treatment ${ }^{c}$ & $82(15.7)$ \\
\hline Within 3 months after end of first-line treatment ${ }^{d}$ & $132(25.3)$ \\
\hline More than 3 months after end of first-line treatment ${ }^{e}$ & $302(58.0)$ \\
\hline Missing data & $5(1.0)$ \\
\hline
\end{tabular}

$\mathrm{N}=$ total number of patients, $\mathrm{n}=$ number of patients, $S D$ standard deviation

a) The study started in 2007, before the label change in April 2008 which restricted the use of pemetrexed to patients with non-squamous cell carcinoma

b) Multiple nominations possible

c) First dose of pemetrexed given $\leq 28$ days after the last dose of first-line therapy

d) First dose of pemetrexed dose given $>28$ days but $\leq 3$ months after the last dose of first-lintherapy

e) First dose of pemetrexed dose given $>3$ months after the last dose of first-line therapy 
age of 66.3 years, and $36.1 \%$ of patients were $\geq 70$ years old. The elderly patients were similar to the overall population in terms of baseline KI and histology (Table 2).

Regarding previous first-line chemotherapy, $86.4 \%$ of all patients had received platinum-based combinations (Table 1). These were carboplatin-based in approximately two thirds of the patients (overall use: carboplatin $68.2 \%$, cisplatin $25.9 \%$ of patients). Median duration of prior chemotherapy was 3.5 months. The majority of patients $(58.0 \%)$ had stopped prior chemotherapy (last dose) more than 3 months before the start of this study.

\section{Dose administration}

The median initial pemetrexed dose was $500 \mathrm{mg} / \mathrm{m}^{2}$ (range 330 to $500 \mathrm{mg} / \mathrm{m}^{2}$ ). Overall, 232 patients $(49.3 \%$ ) had at least one dose delay, but only 33 patients (7.0\%) had a dose delay due to toxicity. Doses were mainly delayed due to scheduling conflicts (35.0\%). At least one dose reduction during the study was documented for 25 (4.8\%) patients. Of these patients, $10(40.0 \%)$ received a dose $\leq 75 \%$ of the previous dose and 1 patient $(4 \%)$ received a dose of $\leq 50 \%$ of the previous dose.

\section{Physician-rated PS (KI)}

In this study, $58.0 \%$ of patients (302 of 521 patients; $95 \%$ CI 53.6\%; 62.2\%) achieved a "KI benefit response" after the second treatment cycle; KI improvement by at least $10 \%$ was achieved in $20.3 \%$ of patients and $37.6 \%$ maintained a high KI of at least $80 \%$ (Table 3 ). Of note, $20.8 \%$ of patients with a poor baseline $\mathrm{KI}<80 \%$ had improved to a KI of at least $80 \%$ after the second treatment cycle (41of 197 patients) (Figure 1). 15.8\% of patients with a high baseline KI (51 of 323 patients) deteriorated to a KI below $80 \%$ after the second cycle,
24 patients had missing data after the second cycle. If patients with missing data were excluded from the analysis, the KI benefit response rate was $64.1 \%$ (95\% CI: $59.6 \% ; 68.5 \%)$. After the sixth treatment cycle, $74.4 \%$ of 254 patients still on treatment showed KI benefit response (95\% CI 68.6\%; 79.7\%). Median KI remained unchanged at $80 \%$ throughout the study.

Figure 2 summarizes the analysis of potential factors associated with the KI benefit response after the second treatment cycle (univariate logistic regression analyses).

There was a significant advantage with respect to achieving KI benefit response after the second treatment cycle for patients who had a KI of $\geq 80 \%$ at baseline ( $p$ $<0.001)$ and for patients who had received first-line combination treatment as when compared with those who had received single-agent treatment $(p=0.005)$. Time elapsed since first-line chemotherapy had no significant impact on KI benefit response. Patients who had experienced Grade 3/4 toxicities during the first 2 treatment cycles had significantly less chance of achieving KI benefit response $(p<0.001)$. These results of the univariate models were supported by multivariable modeling approaches which gave similar results (data not shown).

\section{Patient-rated HR-QoL (EQ-5D)}

Approximately half of the patients returned completed EQ-5D questionnaires and therefore were evaluable for HR-QoL. Patients' mean EQ-5D index at baseline was 0.66 (standard deviation [SD] 0.256; $\mathrm{N}=231$ patients with data available). A small, statistically significant improvement of this score was noted after the second treatment cycle, that is after approximately 6 weeks of treatment (mean increase 0.02, SD 0.214; $\mathrm{N}=190$

Table 2 Disease characteristics by age group

\begin{tabular}{|c|c|c|c|}
\hline & Age $<70$ years $(\mathrm{N}=333) \mathrm{n}(\%)$ & Age $\geq 70$ years $(\mathrm{N}=188) \mathrm{n}(\%)$ & All patients $(\mathrm{N}=521) \mathrm{n}(\%)$ \\
\hline \multicolumn{4}{|l|}{ Histology } \\
\hline Non-squamous cell carcinoma & $283(85.0)$ & $161(85.6)$ & $444(85.2)$ \\
\hline Squamous cell carcinoma ${ }^{a}$ & $50(15.0)$ & $27(14.4)$ & $77(14.8)$ \\
\hline \multicolumn{4}{|l|}{ Disease stage at study entry } \\
\hline Stage IIla & $18(5.4)$ & $17(9.0)$ & $35(6.7)$ \\
\hline Stage IIIb & $65(19.5)$ & $38(20.2)$ & $103(19.8)$ \\
\hline Stage IV & $250(74.1)$ & $133(70.7)$ & $383(73.5)$ \\
\hline \multicolumn{4}{|l|}{ Karnofsky Index (KI) } \\
\hline $\mathrm{KI} \geq 80 \%$ & $207(62.2)$ & $116(61.7)$ & $323(62.0)$ \\
\hline KI 70\% & $89(26.7)$ & $45(23.9)$ & $134(25.7)$ \\
\hline $\mathrm{KI} 60 \%$ & $27(8.1)$ & $18(9.6)$ & $45(8.6)$ \\
\hline $\mathrm{KI} 50 \%$ & $10(3.0)$ & $8(4.3)$ & $18(3.5)$ \\
\hline Missing data & $0(0.0)$ & $1(0.5)$ & $1(0.2)$ \\
\hline
\end{tabular}


Table 3 KI benefit response after the second treatment cycle (worst case scenario)

\begin{tabular}{|c|c|}
\hline & $\mathrm{KI}$ benefit response ${ }^{\mathrm{a}}$ All patients $(\mathrm{N}=521) \mathrm{n}(\%)$ of patients $[95 \% \mathrm{Cl}]$ \\
\hline Responders overall & $302(58.0)[53.6 ; 62.2]$ \\
\hline $0 \%$ improvement of $\mathrm{Kl}$, but maintained $\geq 80 \%$ & $151(29.0)$ \\
\hline $10 \%$ improvement of $\mathrm{Kl}$ & $97(18.6)$ \\
\hline $20 \%$ improvement of $\mathrm{Kl}$ & $7(1.3)$ \\
\hline $30 \%$ improvement of $\mathrm{KI}$ & $2(0.4)$ \\
\hline Worsening of $\mathrm{Kl}$, but still maintained $\geq 80 \%$ & $45(8.6)$ \\
\hline Non-responders, overall & $219(42.0)[37.8 ; 46.4]$ \\
\hline $0 \%$ worsening of $\mathrm{Kl}$, but maintained $<80 \%$ & $67(12.9)$ \\
\hline Deterioration of $\mathrm{Kl}$, developed $\mathrm{Kl}<80 \%$ & $102(19.6)$ \\
\hline Missing data ${ }^{b}$ & 50 ( 9.6) \\
\hline
\end{tabular}

$\mathrm{Cl}$ confidence interval, $K I$ Karnofsky Index, $\mathrm{N}=$ total number of patients, $\mathrm{n}=$ number of patients

a) Defined as improvement in $\mathrm{KI}$ of at least $10 \%$ (absolute) or maintenance/achievement of an absolute $\mathrm{KI}$ of at least $80 \%$

b) Patients who discontinued prior to the end of the second treatment cycle or who had missing KI data were considered as non-responders (worst case scenario)

patients; $p=0.003$ ). For those patients remaining on study, the EQ-5D index continued to improve up to treatment cycle 6 (mean increase 0.11, SD 0.228; $\mathrm{N}=61$ patients; $p<0.001$ ). Figure 3 presents patients' mean EQ-5D ratings for the 5 individual EQ-5D domains at baseline and after the second, fourth and sixth treatment cycle. For the pain/discomfort and anxiety/depression dimensions, improvements had started after the second treatment cycle. Improvements in mobility and usual activities became visible after the fourth cycle only.
Patient self-care worsened initially after the second cycle, but then improved up to treatment cycle 6 .

Patients' self-ratings of overall health status on the EQ-VAS gave consistent results. The mean baseline EQVAS score was 59.3 (SD 17.80; $\mathrm{N}=225$ patients). There was a small, statistically significant improvement after the second cycle (mean increase 3.3, SD 12.58; $\mathrm{N}=182$ patients; $p<0.001)$. EQ-VAS ratings continued to improve significantly up to treatment cycle 6 (mean increase 12.8, SD 17.62; $\mathrm{N}=60$ patients; $p<0.001$ ).

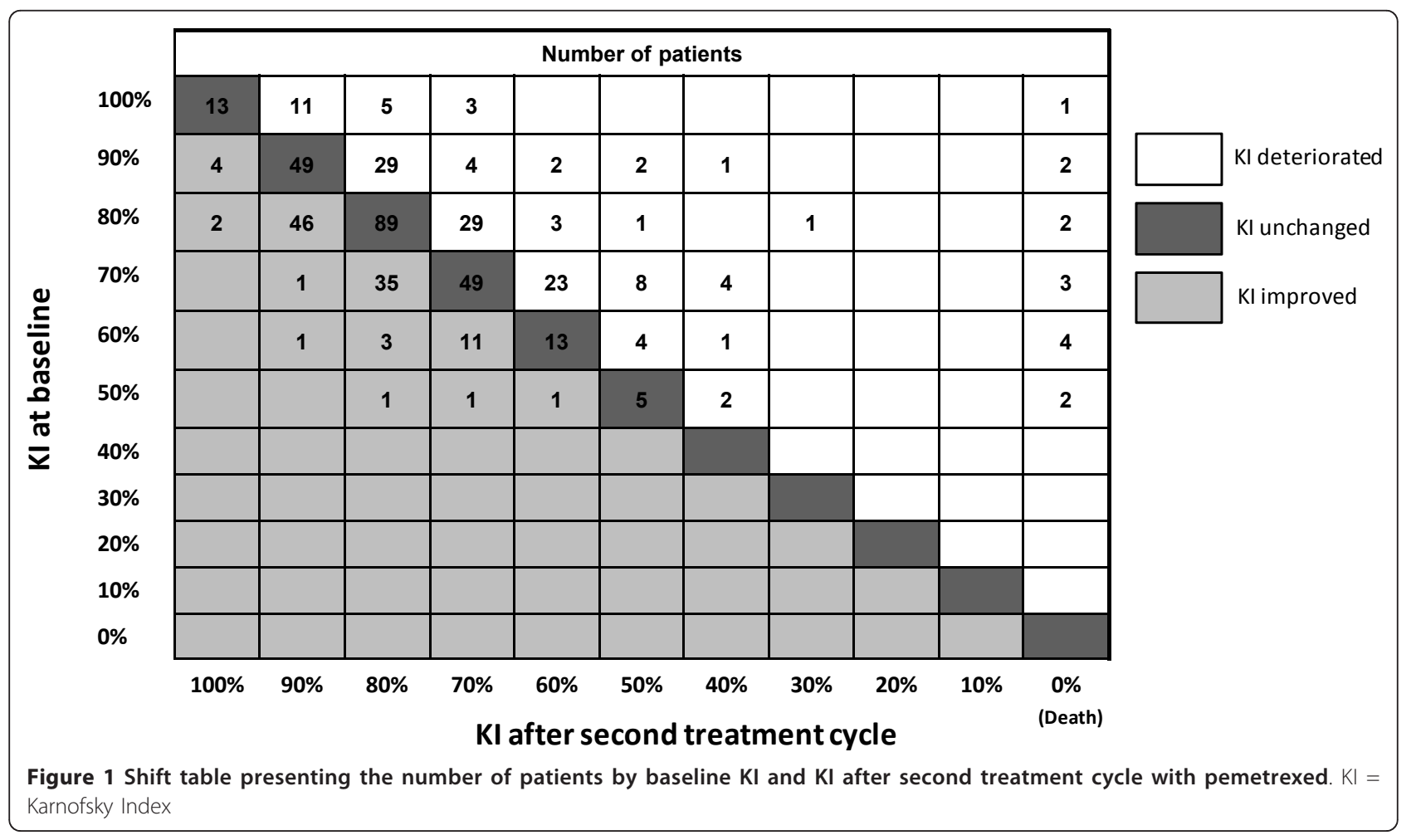




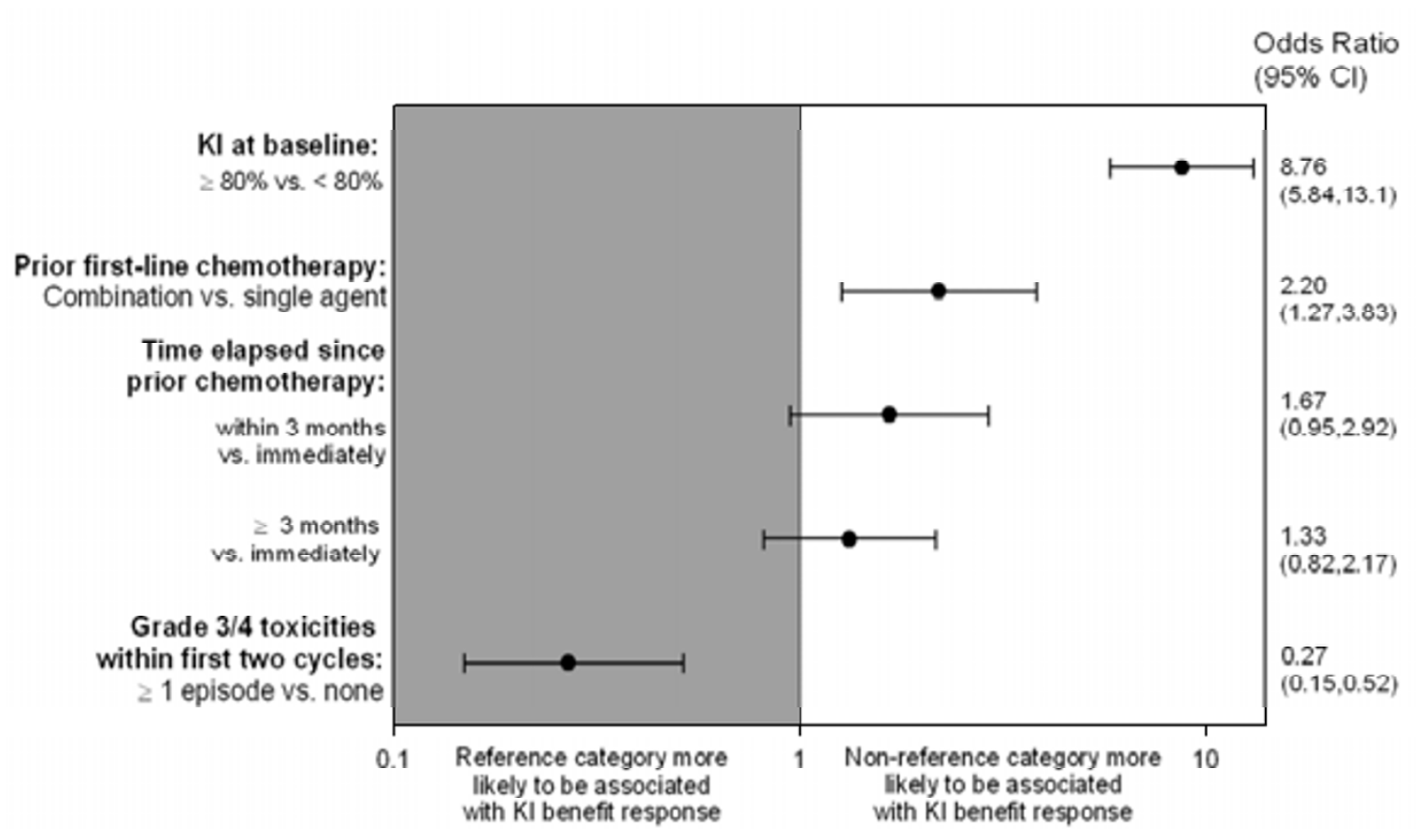

Figure 2 Odds ratios for patients' characteristics potentially associated with $\mathrm{KI}$ benefit response after the second treatment cycle. $\mathrm{Cl}=$ confidence interval, $\mathrm{Kl}=$ Karnofsky Index. Odds ratios derived from univariate regression analyses, including all eligible patients $(\mathrm{N}=521)$. Reference categories: $\mathrm{Kl}$ at baseline $=<80 \%$, prior first-line chemotherapy $=$ single agent, time elapsed since prior chemotherapy $=$ immediately, Grade $3 / 4$ toxicities $=$ none. Time elapsed since prior chemotherapy: Immediately $=$ first dose of pemetrexed given $\leq 28$ days after the last dose of first-line therapy. Within 3 months = first dose of pemetrexed given $>28$ days but $\leq 3$ months after the last dose of first-line therapy. Later than 3 months: first dose of pemetrexed given $>3$ months after the last dose of first-line therapy

\section{Disease control and overall survival}

The overall disease control rate, with disease control defined as physician-evaluated best response of complete or partial response or stable disease, was $60.3 \%$ (314 patients; 95\% CI 55.9\%; 64.5\%). After a median followup time of 13.8 months, the median survival time was 11.1 months (95\% CI 9.5 months; 12.2 months). The 12month survival rate was $45.8 \%$ (95\% CI 40.7\%; 50.7\%), $25.6 \%$ of patients were still at risk (i.e., still under follow-up).

Solicited toxicities, weight control and blood transfusions The analysis of toxicities which were collected by solicited questioning included 516 patients who received at least one dose of pemetrexed. Overall, any Grade 3/4 toxicities were reported for $23.8 \%$ of patients. Two patients $(0.4 \%)$ died due to toxicity during the first treatment cycle. Grade 3/4 toxicities reported for these patients included febrile neutropenia for one patient (male, 65 years, KI 90\%), and fatigue/asthenia, mucositis, neutropenia, and stomatitis/pharyngitis for the second patient (male, 69 years, KI 70\%). Grade 3/4 toxicities occurred most frequently during the initial cycle $(11.0 \%$ of patients), less frequently during cycles 2 to 4 ( $8.5 \%$, $9.0 \%$, and $9.3 \%$ of patients, respectively), and then decreased sharply after the fourth cycle $(<5 \%$ for all cycles after cycle 4).

Table 4 summarizes the frequency of these solicited toxicities by maximum toxicity grade as evaluated by the physicians, for all patients, by baseline KI status and by age group. Grade 3/4 toxicities reported in more than $2 \%$ of patients were fatigue/asthenia (15.9\%), neutropenia $(8.7 \%)$ and nausea $(3.1 \%)$. Grade $3 / 4$ toxicity rates were twice as high in patients with poor baseline KI (<80\%) when compared to patients with a baseline KI of $\geq 80 \%$ ( $34.7 \%$ vs. $17.4 \%$; see Table 4$)$. There was no evidence that Grade 3/4 toxicity rates were higher in elderly than in younger patients ( $\geq 70$ vs. $<70$ years).

Analysis of body weight showed that weight loss was rare. Only $5.4 \%$ of all patients lost $\geq 10 \%$ of body weight during the period of documentation. Red blood cell (RBC) transfusions were required by $24.2 \%$ of patients at some time during the study; $9.2 \%$ of patients received a RBC transfusion at baseline, $3.9 \%$ and $5.5 \%$ of patients received $\mathrm{RBCs}$ at the time of the first and second pemetrexed treatment, respectively (Table 5). Platelet transfusions were required by $3.5 \%$ of patients, colonystimulating factors were administered to $11.1 \%$ of patients. $95.2 \%$ of patients received dexamethasone prophylaxis (or other steroids) at some time during the 


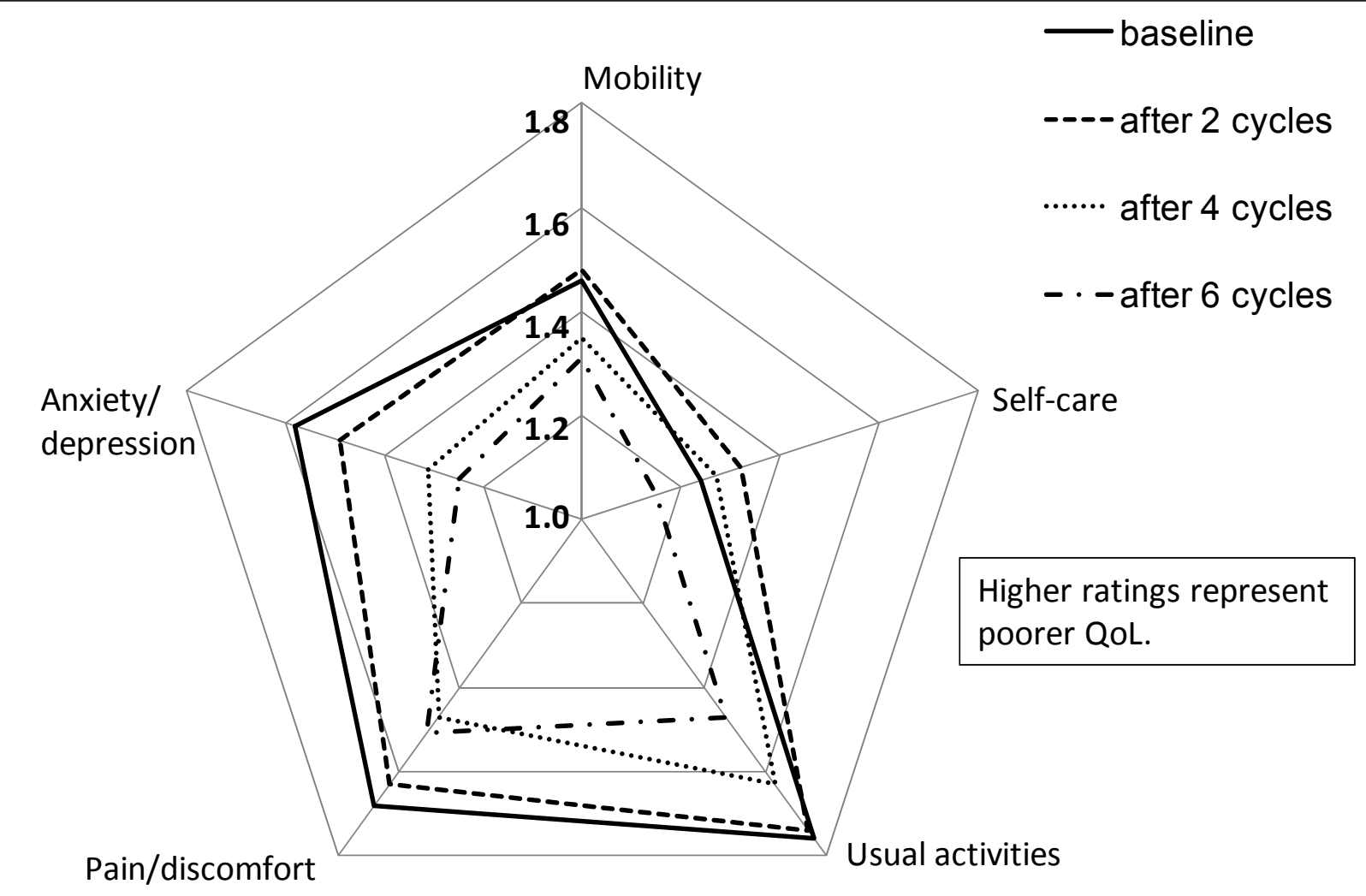

Figure 3 EQ-5D health status profiles: mean ratings for each of the 5 dimensions of the EQ- 5D questionnaire over time. On the EQ-5D questionnaire, the patient rates each of the 5 dimensions (mobility, self care, usual activities, pain/discomfort and anxiety/depression) as associated with "some problems" (= 1), moderate problems (=2), extreme problems (=3). EQ- 5D = European Quality Of Life Five Dimensions questionnaire, QoL = Quality Of Life, $\mathrm{n}=$ number of patients

study, $97.3 \%$ of patients received at least one dose of vitamin $\mathrm{B}_{12}$. Further, $83.5 \%$ of patients received antiemetics, $74.3 \%$ received analgesics, and $12.7 \%$ received antidiarrheals. Intake of at least one dose of folic acid was documented by $98.3 \%$ out of 292 patients with diary information available [24].

\section{Discussion}

Second-line treatment improves survival and is increasingly used in patients with advanced NSCLC $[2,5,25]$. Prospective data evaluating patients' overall health condition during second-line treatment as reflected by PS or HR-QoL are still rare, in particular for elderly

Table 4 Solicited Grade 3/4 toxicities (physician evaluation) by baseline $\mathrm{KI}$ and age group

\begin{tabular}{|c|c|c|c|c|c|}
\hline \multirow[b]{2}{*}{ Toxicity } & \multicolumn{5}{|c|}{ n (\%) of patients with maximum Grade $3 / 4$ toxicity } \\
\hline & $\begin{array}{l}\text { All patients treated } \\
(\mathrm{N}=516)\end{array}$ & $\begin{array}{c}\text { Baseline } \mathrm{KI} \geq 80 \% \\
(\mathrm{~N}=322)\end{array}$ & $\begin{array}{c}\text { Baseline } \mathrm{KI}<80 \% \\
(\mathrm{~N}=193)\end{array}$ & $\begin{array}{c}\text { Age }<70 \text { years } \\
(\mathrm{N}=329)\end{array}$ & $\begin{array}{c}\text { Age } \geq 70 \text { years } \\
(\mathrm{N}=187)\end{array}$ \\
\hline Any toxicity & $123(23.8)$ & $56(17.4)$ & $67(34.7)$ & $87(26.4)$ & $36(19.3)$ \\
\hline Fatigue/asthenia & $82(15.9)$ & $32(9.9)$ & $50(25.9)$ & $54(16.4)$ & $28(15.0)$ \\
\hline Neutropenia & $45(8.7)$ & $21(6.5)$ & $24(12.4)$ & $30(9.1)$ & $15(8.0)$ \\
\hline Nausea & $16(3.1)$ & $6(1.9)$ & $10(5.2)$ & $10(3.0)$ & $6(3.2)$ \\
\hline Febrile neutropenia & $10(1.9)$ & $3(0.9)$ & $7(3.6)$ & $6(1.8)$ & $4(2.1)$ \\
\hline Rash/desquamation & $7(1.4)$ & $6(1.9)$ & $1(0.5)$ & $4(1.2)$ & $3(1.6)$ \\
\hline Stomatitis/pharyngitis & $7(1.4)$ & $3(0.9)$ & $4(2.1)$ & $3(0.9)$ & $4(2.1)$ \\
\hline Mucositis & $5(1.0)$ & $1(0.3)$ & $4(2.1)$ & $3(0.9)$ & $2(1.1)$ \\
\hline Vomiting & $5(1.0)$ & $2(0.6)$ & $3(1.6)$ & $4(1.2)$ & $1(0.5)$ \\
\hline Diarrhea & $2(0.4)$ & $1(0.3)$ & $1(0.5)$ & $2(0.6)$ & $0(0.0)$ \\
\hline
\end{tabular}


Table 5 Disease- or treatment related concomitant medication as reported by physicians

\begin{tabular}{|c|c|c|c|c|c|c|c|c|c|}
\hline Cycle & $N$ & $\begin{array}{l}\text { Analgesics } \\
\text { n (\%) }\end{array}$ & $\begin{array}{c}\text { Antiemetics } \\
\text { n (\%) }\end{array}$ & $\begin{array}{c}\text { Antidiarrheals } \\
\text { n (\%) }\end{array}$ & $\begin{array}{l}\text { Dexa or similar } \\
\text { steroids n (\%) }\end{array}$ & CSF n (\%) & $\begin{array}{c}\text { Other } \\
\text { medications n } \\
\text { (\%) }\end{array}$ & $\begin{array}{c}\mathrm{RBC} \\
\text { transfusions } \mathrm{n} \\
(\%)\end{array}$ & $\begin{array}{c}\text { Platelet } \\
\text { transfusions } \mathrm{n} \\
\text { (\%) }\end{array}$ \\
\hline Overall & 521 & $387(74.3)$ & 435 (83.5) & 66 (12.7) & $496(95.2)$ & $58(11.1)$ & $292(56.0)$ & $126(24.2)$ & $18(3.5)$ \\
\hline Baseline & 521 & $270(51.8)$ & $182(34.9)$ & $6(1.2)$ & $244(46.8)$ & $12(2.3)$ & $187(35.9)$ & $48(9.2)$ & $5(1.0)$ \\
\hline Cycle 1 & 516 & $265(51.4)$ & $270(52.3)$ & $7(1.4)$ & 452 (87.6) & $5(1.0)$ & $196(38.0)$ & 20 ( 3.9$)$ & $2(0.4)$ \\
\hline Cycle 2 & 471 & $242(51.4)$ & $288(61.1)$ & $20(4.2)$ & $430(91.3)$ & $14(3.0)$ & $201(42.7)$ & $26(5.5)$ & $0(0.0)$ \\
\hline Cycle 3 & 421 & $226(53.7)$ & $260(61.8)$ & 16 ( 3.8$)$ & $391(92.9)$ & $14(3.3)$ & $186(44.2)$ & $29(6.9)$ & $4(1.0)$ \\
\hline Cycle 4 & 344 & $178(51.7)$ & 215 (62.5) & $15(4.4)$ & $327(95.1)$ & $17(4.9)$ & $155(45.1)$ & 30 ( 8.7) & $3(0.9)$ \\
\hline Cycle 5 & 278 & $142(51.1)$ & $179(64.4)$ & $8(2.9)$ & $268(96.4)$ & $11(4.0)$ & $137(49.3)$ & $14(5.0)$ & $1(0.4)$ \\
\hline Cycle 6 & 254 & $129(50.8)$ & $168(66.1)$ & $7(2.8)$ & $244(96.1)$ & $9(3.5)$ & $125(49.2)$ & $15(5.9)$ & $0(0.0)$ \\
\hline Cycle 7 & 150 & $93(62.0)$ & $87(58.0)$ & $4(2.7)$ & 143 (95.3) & $4(2.7)$ & $96(64.0)$ & $7(4.7)$ & $0(0.0)$ \\
\hline Cycle 8 & 135 & $88(65.2)$ & $64(47.4)$ & $5(3.7)$ & $131(97.0)$ & $4(3.0)$ & 87 (64.4) & $6(4.4)$ & $1(0.7)$ \\
\hline Cycle 9 & 110 & 75 (68.2) & $52(47.3)$ & $2(1.8)$ & $105(95.5)$ & $1(0.9)$ & $77(70.0)$ & $4(3.6)$ & $0(0.0)$ \\
\hline Final & 516 & $289(56.0)$ & $253(49.0)$ & $21(4.1)$ & $317(61.4)$ & $25(4.8)$ & 203 (39.3) & $60(11.6)$ & $8(1.6)$ \\
\hline
\end{tabular}

CSF colony stimulating factors, Dexa dexamethasone, $\mathrm{N}=$ number of patients per cycle, $R B C$ red blood cells

patients or patients with poor PS as frequently treated in routine clinical practice. Patients older than 70 years are of special interest; even their first-line treatment is under continuous debate $[25,26]$ because multimorbidity and a higher incidence of toxicities are assumed to reduce their overall clinical treatment benefit.

sOur study demonstrates that the majority of patients with Stage III/IV NSCLC in routine clinical practice can maintain or improve physician-rated PS (KI) and patientrated HR-QoL (EQ-5D) during second-line treatment with single-agent pemetrexed. Our population included $36 \%$ of elderly patients. The majority of all patients (58.0\%) achieved KI benefit response after the second treatment cycle (with $90 \%$ of patients still on study), and KI benefit response rates increased further during the subsequent cycles. Without second-line treatment, PS and HR-QoL would most likely have declined due to the disease progression. Even with treatment, a decline in PS and HR-QoL would be expected for patients with disease progression or major toxicities. Correspondingly, patients who had experienced no Grade 3/4 toxicities during the first 2 cycles had a significant advantage with respect to achieving KI benefit response. Patients with high baseline KI also had a significant advantage with respect to achieving KI benefit response, indicating that it is important to optimize patients' general condition before starting second-line treatment.

Several studies have underlined the importance of considering PS for clinical practice. Lilenbaum et al. found high prevalences of poor PS (Eastern Cooperative Oncology Group [ECOG] PS 2-4, corresponding to a KI $<80 \%$ ) in lung cancer patients of $34 \%$ when rated by physicians and of $48 \%$ when rated by patients [10]. Blagden et al. showed that both patient-and physician-rated PS scores reflected duration of survival and disease stage; physician-rated scores were only marginally more predictive of survival [8]. A recent study in more than 26,000 NSCLC patients has shown that PS is an independent risk factor for patient OS [11].

No previous study has looked at changes in PS during second-line treatment. Only one post-hoc analysis of data from a first-line treatment study has been published by Sculier et al. [27]. In their study, 485 patients received three cycles of triple-agent treatment with cisplatin, gemcitabine and ifosfamide. $25 \%$ of patients who had a poor baseline KI of $60 \%$ to $70 \%$ achieved clinical improvement, defined as high KI of $\geq 80 \%$. These findings are consistent with the improvement rate of $20.8 \%$ in patients with poor baseline KI we observed with second-line pemetrexed treatment.

We additionally looked at patient-rated HR-QoL, using the EQ-5D self-estimation instrument. The EQ$5 \mathrm{D}$ was chosen because it is a simple, validated and commonly used questionnaire which can be completed within a short time [15]. The disease-specific, multidimensional tools commonly used in lung cancer studies, such as the Lung Cancer Symptom Scale (LCSS) used by Hanna et al. [6] in a study which compared secondline treatment with pemetrexed versus docetaxel, were too complex for use in a routine clinical practice setting. The EQ-5D has been validated into 36 official languages (http://www.euroqol.org), including the German language [28]. We found that on average, baseline EQ-5D ratings were at least maintained, consistent with the physician-based KI ratings. Mean EQ-5D index and EQVAS scores even showed small improvements after the second treatment cycle, i.e., as early as 6-weeks after the initiation of pemetrexed treatment. The EQ-5D instrument has rarely been used in NSCLC patients so far. Grutters et al. have recently applied the EQ-5D in 
patients surviving lung cancer. They found that patients with severe adverse events (dyspnoea grade $\geq 3$ ) during treatment had statistically significantly lower EQ-5D index scores than patients without severe adverse events [29], indicating that the instrument is sensitive enough to detect health status changes during chemotherapy.

In our study, second-line pemetrexed treatment was well tolerated by most patients. Two of 516 patients $(0.4 \%)$ died due to drug-related toxicity. There were no signs of cumulative toxicities. On the contrary, Grade 3/4 toxicity rates decreased after repeated treatment cycles. Patients in our study received a higher number of treatment cycles than in the randomized phase III trial of second-line pemetrexed treatment by Hanna et al. [6] which allowed for treatment up to disease progression (median 5 vs. 4 cycles). In our study, $20 \%$ of patients received at least 9 cycles and 5\% continued pemetrexed treatment after the end of study. Considering in addition that most patients maintained or improved their PS and HR-QoL, our data indicate that a high number of treatment cycles do not impair patients' quality of life.

The Grade 3/4 toxicity profile, recorded by solicited questioning of specific non-hematologic toxicities, was largely comparable to the unsolicited toxicity rates during pemetrexed treatment published by Hanna et al. (e.g. febrile neutropenia $1.9 \%$ vs. $1.9 \%$, nausea $3.1 \%$ vs. $2.6 \%$, vomiting $1.5 \%$ vs. $1.0 \%$, rash $1.4 \%$ vs. $0.8 \%$ ). However, we found higher rates of Grade 3/4 asthenia/fatigue (15.9\% vs. $5.3 \%$ ) and Grade $3 / 4$ neutropenia ( $8.7 \%$ vs. $5.3 \%$ ).

Further, we found no evidence that Grade 3/4 toxicity rates were higher in elderly than in younger patients. These findings are well in line with a subgroup analysis of toxicities in the Hanna study, performed by Weiss et al., which also did not find any significant difference in toxicities between older and younger patients ( $\geq 70$ vs. $<70$ years) [30]. A previous metaanalysis of 3 studies on pemetrexed first-line treatment in 764 NSCLC patients also concluded that pemetrexed or pemetrexed-based combinations produced similar treatment effects in older and younger patients ( $\geq 65$ and $<65$ years) and appeared to be well tolerated in the elderly population [31]. Thus, it cannot be stated in general that treatment toxicity is higher in elderly patients; this may depend on the type of treatment used. A recent retrospective study by Chrischilles et al. evaluated chemotherapy use and adverse events during treatment of advanced NSCLC in routine clinical practice and concluded that toxicity was increased in elderly patients, but his study mainly looked at first-line treatment with platinum-based combinations [32]. One additional result of this US study was that physicians used carboplatin-based combinations more frequently than cisplatin-based combinations (65.3\% vs. $10.4 \%)$. Our German and Austrian data were fully consistent with these findings: Physicians used carboplatin- based combinations as first-line treatment in approximately two thirds of patients (carboplatin 62.8\%, cisplatin 25.9\%). Administration of carboplatin is more convenient and less emetogenic than cisplatin [33], and carboplatin has been associated with less toxicity [34]. This may explain why the latter is preferred in routine clinical practice.

Our study has limitations. First, the non-interventional design to observe patients in routine clinical practice prohibits any definite conclusion on the efficacy of second-line pemetrexed treatment. In particular, tumor response data are of limited value and cannot be compared to clinical trial data because physicians may not have performed standard radiologic assessments or classified response in accordance with the standard response evaluation criteria in solid tumors (RECIST). Second, our toxicity data cannot be directly compared with toxicity data from clinical trials, because the collection of toxicities differed substantially: only a few solicited toxicities were specifically asked for via tick-boxes; no complete lists of Common Terminology Criteria for Adverse Events (CTC-AE) were handed out to the investigators. Patients may also have reported e.g. fatigue more frequently due to the solicited questioning for specific toxicities. The validity of these data may therefore be questioned, although the majority of toxicity results were in line with previous clinical studies of pemetrexed [6]. Further, we did not differentiate between in-and outpatient treatment although it can be assumed that the majority of patients received the 10-minute infusion either in outpatient practice or in the ambulance of the hospital. Finally, only half of the patients returned completed EQ-5D questionnaires. The internal validity of our QoL data may therefore be compromised because the missing data may be informative and not at random. The major strength of our study is that we looked at second-line treatment in a large sample of patients as routinely treated in clinical practice where there is a particular lack of data [6]. Clinical trials in NSCLC patients are often criticized for rarely enrolling elderly patients or patients with poor PS. In the randomized phase III trial by Hanna et al., $15.1 \%$ of patients in the pemetrexed arm were $\geq 70$ years old, and $10.6 \%$ of patients had a poor baseline ECOG-PS of $2[6,30]$. In our study, $36.1 \%$ of patients were $\geq 70$ years of age, and $37.8 \%$ of patients had a poor baseline KI of $<80 \%$. Despite the higher proportions of elderly and poor-performance patients in our study, overall disease control rates with pemetrexed were comparable to those found by Hanna et al. (60.3\% vs. 54.9\%).

\section{Conclusions}

In this large non-interventional study of second-line pemetrexed treatment in patients with Stage III/IV 
NSCLC, including $36 \%$ elderly ( $\geq 70$ years) patients, physician-rated PS (KI) and patient-rated HR-QoL (EQ5D) were maintained or improved in the majority of patients. Both, physician-rated PS and patient-rated HRQoL assessments should, perhaps, be given more weight than minor radiologic changes in guiding treatment decisions and evaluating the effectiveness of second-line therapy. Patients with high baseline PS also had a significant advantage, showing that it is important to optimize the patients' general condition before starting treatment. Treatment was well-tolerated by the majority of patients and there were no signs of cumulative toxicities. Patients received a higher number of treatment cycles than in clinical trials of second-line pemetrexed treatment; considering that most patients maintained or improved their PS and HR-QoL, our data indicate that a high number of treatment cycles do not impair patients' quality of life. Grade 3/4 toxicity rates were higher in patients with poor baseline PS, but not in elderly versus younger patients, indicating that elderly patients can be considered for second-line treatment with pemetrexed if they have a high PS of $\geq 80$.

\section{Acknowledgements}

The study was funded by Lilly Deutschland GmbH, Bad Homburg, Germany. The authors are indebted to all study investigators for their contribution to data acquisition and patient care. Karin Helsberg (PhD), Trilogy Writing \& Consulting, Frankfurt, Germany, provided medical writing support for this manuscript. PRIMO Scientific Corporation, Panama, Republic of Panama, supported the preparation of figures. Statistical analyses were programmed by Accovion GmbH, Eschborn, Frankfurt, Germany.

\section{Author details \\ 'Hospital Martha-Maria, Halle-Doelau, Department of Internal Medicine II, Halle, Germany. ${ }^{2}$ Hospital Bethanien, Group Practice Oncology, Frankfurt, Germany. ${ }^{3}$ Medical Department, Lilly Deutschland GmbH, Bad Homburg, Werner-Reimers Straße 2-4, 61352 Bad Homburg, Germany. ${ }^{4}$ Statistics Oncology, Lilly Deutschland GmbH, Bad Homburg, Germany.}

\section{Authors' contributions}

CS and HB participated in the design of the study. $\mathrm{HB}$ and TK were involved in the conduct of the study. VS was responsible for the statistical analysis and drafted the manuscript supported by a medical writer. All authors contributed to data interpretation and revised the draft critically for scientific content. All authors read and approved the final version of the manuscript.

\section{Competing interests}

WS has served as consultant for and has received research grants from Lilly Deutschland GmbH, Bad Homburg, Germany. HT has served as consultant for and has received honoraria from Sanofi Aventis, Roche Pharma AG, Norvartis, Glaxo Smith Kline, Pfizer and Hexal. HB, TK, VS and CS are employees of Lilly Deutschland GmbH, Bad Homburg, Germany, HB and TK own Eli Lilly stocks.

Received: 8 June 2011 Accepted: 13 January 2012

Published: 13 January 2012

\section{References}

1. Barlesi F, Jacot W, Astoul P, Pujol JL: Second-line treatment for advanced non-small cell lung cancer: a systematic review. Lung Cancer 2006, 51:159-172.

2. Noble J, Ellis PM, Mackay JA, Evans WK, Lung Cancer Disease Site Group of Cancer Care Ontario's Program in Evidence-based Care: Second-line or subsequent systemic therapy for recurrent or progressive non-small cell lung cancer: A systematic review and practice guideline. J Thorac Oncol 2006, 1:1042-1058

3. Tassinari D, Scarpi E, Sartori S, Tamburini E, Santelmo C, Tombesi P, LazzariAgli L: Second-line treatments in non-small cell lung cancer. A systematic review of literature and metaanalysis of randomized clinical trials. Chest 2009, 135:1596-1609.

4. Tassinari D, Drudi F, Lazzari-Agli L, Tombesi P, Sartori S: Second-line treatments of advanced non-small-cell lung cancer: new evidence for clinical practice. Ann Oncol 2010, 21:428-429.

5. Cella DF, Patel JD: Improving health-related quality of life in non-smallcell lung cancer with current treatment options. Clin Lung Cancer 2008, 9:206-212.

6. Hanna N, Shepherd FA, Fossella FV, Pereira JR, De Marinis F, von Pawel J, Gatzemeier U, Tsao TC, Pless M, Muller T, Lim HL, Desch C, Szondy K, Gervais R, Shaharyar, Manegold C, Paul S, Paoletti P, Einhorn L, Bunn PA Jr: Randomized phase III trial of pemetrexed versus docetaxel in patients with non-small-cell lung cancer previously treated with chemotherapy. J Clin Oncol 2004, 22:1589-1597.

7. Krzakowski M, Ramlau R, Jassem J, Szczesna A, Zatloukal P, Von Pawel J, Sun X, Bennouna J, Santoro A, Biesma B, Delgado FM, Salhi Y, Vaissiere N, Hansen O, Tan EH, Quoix E, Garrido P, Douillard JY: Phase III trial comparing vinflunine with docetaxel in second-line advanced nonsmall-cell lung cancer previously treated with platinum-containing chemotherapy. J Clin Oncol 2010, 28:2167-2173.

8. Blagden SP, Charman SC, Sharples LD, Magee LR, Gilligan D: Performance status score: do patients and their oncologists agree? Br J Cancer 2003, 89:1022-1027.

9. Dajczman E, Kasymjanova G, Kreisman H, Swinton N, Pepe C, Small D: Should patient-rated performance status affect treatment decisions in advanced lung cancer? J Thorac Oncol 2008, 3:1133-1136.

10. Lilenbaum RC, Cashy J, Hensing TA, Young S, Cella D: Prevalence of poor performance status in lung cancer patients. Implications for Research J Thorac Oncol 2008, 3:125-129.

11. Kawaguchi T, Takada M, Kubo A, Matsumura A, Fukai S, Tamura A, Saito R, Maruyama Y, Kawahara M, Ignatius Ou SH: Performance Status and Smoking Status Are Independent Favorable Prognostic Factors for Survival in Non-small Cell Lung Cancer. J Thorac Oncol 2010, 5:620-630.

12. Ries LAG, Melbert D, Krapcho M: SEER Cancer Statistics Review, 19752005, NationalCancer Institute. Bethesda, MD, National Cancer Institute; [http://seer.cancer.gov/csr/1975_2005/].

13. Pallis AG, Gridelli C, van Meerbeeck JP, Greillier L, Wedding U, Lacombe D, Welch J, Belani CP, Aapro M: EORTC Elderly Task Force and Lung Cancer Group and International Society for Geriatric Oncology (SIOG) experts' opinion for the treatment of non-small-cell lung cancer in an elderly population. Ann Oncol 2010, 21:692-706.

14. Fleming ID, Cooper JS, Henson DE, Hutter RVP: AJJC Cancer Staging Manual.Edited by: American Joint Committee on Cancer. Philadelphia, PA: Lippincott-Raven Publishers; , 5 1997:.

15. Scagliotti GV, Parikh P, von Pawel J, Biesma B, Vansteenkiste J, Manegold C, Serwatowski P, Gatzemeier U, Digumarti R, Zukin M, Lee JS, Mellemgaard A, Park K, Patil S, Rolski J, Goksel T, de Marinis F, Simms L, Sugarman KP, Gandara D: Phase III study comparing cisplatin plus gemcitabine with cisplatin plus pemetrexed in chemotherapy-naive patients with advanced-stage non-small-cell lung cancer. J Clin Oncol 2008, 26:3543-3551.

16. Scagliotti G, Hanna N, Fossella F: The differential efficacy of pemetrexed according to NSCLC histology: a review of two Phase III studies. Oncologist 2009, 14:253-263.

17. Karnofsky DA, Burchenal JH: The Clinical Evaluation of Chemotherapeutic Agents in Cancer. In Evaluation of Chemotherapeutic Agents Columbia Univ Press; 1949, 196.

18. Brooks R: EuroQol: the current state of play. Health Policy 1996, 37:53-72.

19. Dolan P: Modeling valuations for EuroQol health states. Medical Care 1997, 35:1095-1108.

20. Leemis LM, Trivedi KS: A comparison of approximate interval estimators for the Bernoulli parameter. Am Stat 1996, 50:63-68.

21. Kaplan $E$, Meier P: Nonparametric estimation from incomplete observations. J Am Stat Assoc 1958, 53:457-481.

22. Brookmeyer R, Crowley J: A confidence Interval for the median survival time. Biometrics 1982, 38:29-41. 
23. Shuster JJ: Median follow up in clinical trials. J Clin Oncol 1991, 9:191-192.

24. Schuette $W$, Tesch $H$, Buettner H, Krause T, Soldatenkova V: Compliance to Vitamin Supplementation and Toxicity during 2nd Line Treatment with Pemetrexed in Patients with Stage III/IV Non Small Cell Lung Cancer (NSCLC) in Daily Practice [abstract]. Ann Oncol 2010, 21(Suppl 8):viii, 146 (435P).

25. Kim YH, Yoh K, Niho S, Goto K, Ohmatsu H, Kubota K, Nishiwaki Y: Trends in chemotherapy for elderly patients with advanced non-small-cell lung cancer. Respiratory Medicine 2010, 104:434-439.

26. Quoix EA, Oster J, Westeel V, Pichon E, Zalcman G, Baudrin L, Lavole A, Dauba J, Lebitasy M, Milleron BJ, on behalf of IFCT: Weekly paclitaxel combined with monthly carboplatin versus single-agent therapy in patients age 70 to 89: IFCT-0501 randomized phase III study in advanced non-small cell lung cancer (NSCLC) [abstract]. J Clin Oncol 2010, 28:s18, (abstr 2).

27. Sculier JP, Lafitte JJ, Paesmans M, Lecomte J, Alexopoulos CG, Van Cutsem O, Giner V, Efremidis A, Berchier MC, Collon T, Meert AP, Scherpereel A, Ninane V, Koumakis G, Vaslamatzis MM, Leclercq N, Berghmans T, European Lung Cancer Working Party: Chemotherapy improves low performance status lung cancer patients. Eur Respir J 2007, 30:1186-1192.

28. von der Schulenburg JM, Claes CH, Greiner W, Uber A: Die deutsche Version des EuroQoL-Fragebogens. Zeitschrift für Gesundheitswissenschaften 1998, 6:3-20.

29. Grutters JP, Joore MA, Wiegman EM: Health-related quality of life in patients surviving non-small cell lung cancer. Thorax 2010, 65:903-907.

30. Weiss GJ, Langer C, Rosell R, Hanna N, Shepherd F, Einhorn LH, Nguyen B, Paul S, McAndrews P, Bunn PA Jr, Kelly K: Elderly Patients Benefit From Second-Line Cytotoxic Chemotherapy: A Subset Analysis of a Randomized Phase III Trial of Pemetrexed Compared With Docetaxel in Patients With Previously Treated Advanced Non-Small-Cell Lung Cancer. J Clin Oncol 2008, 24:4405-4411.

31. Kulkarni PM, Chena R, Anand T, Monberg MJ, Obasaju CK: Efficacy and safety of pemetrexed in elderly cancer patients: Results of an integrated analysis. Critical Rev Oncol Hematol 2008, 67:64-70.

32. Chrischilles EA, Pendergast JF, Kahn KL, Wallace RB, Moga DC, Harrington DP, Kiefe Cl, Weeks JC, West DW, Zafar SY, Fletcher RH: Adverse Events Among the Elderly Receiving Chemotherapy for Advanced NonSmall-Cell Lung Cancer. J Clin Oncol 2010, 28:620-627.

33. Grønberg BH, Bremnes RM, Fløtten O, Amundsen T, Brunsvig PF, Hjelde HH, Kaasa S, von Plessen C, Stornes F, Tollåli T, Wammer F, Aasebø U,

Sundstrøm S: Phase III study by the Norwegian lung cancer study group: pemetrexed plus carboplatin compared with gemcitabine plus carboplatin as first-line chemotherapy in advanced non-small-cell lung cancer. J Clin Oncol 2009, 27:3217-3224.

34. Ardizzoni A, Boni L, Tiseo M, Fossella FV, Schiller JH, Paesmans M, Radosavljevic D, Paccagnella A, Zatloukal P, Mazzanti P, Bisset D, Rosell R: CISCA (CISplatin versus CArboplatin) Meta-analysis Group: Cisplatinversus carboplatin-based chemotherapy in first-line treatment of advanced non-small-cell lung cancer: an individual patient data metaanalysis. J Natl Cancer Inst 2007, 99:847-857.

\section{Pre-publication history}

The pre-publication history for this paper can be accessed here: http://www.biomedcentral.com/1471-2407/12/14/prepub

doi:10.1186/1471-2407-12-14

Cite this article as: Schuette et al:: Second-line Treatment of Stage III/IV Non-Small-Cell Lung Cancer (NSCLC) with pemetrexed in routine clinical practice: Evaluation of performance status and health-related quality of life. BMC Cancer 2012 12:14.

\section{Submit your next manuscript to BioMed Central and take full advantage of:}

- Convenient online submission

- Thorough peer review

- No space constraints or color figure charges

- Immediate publication on acceptance

- Inclusion in PubMed, CAS, Scopus and Google Scholar

- Research which is freely available for redistribution

Submit your manuscript at www.biomedcentral.com/submit
Biomed Central 